\title{
BMJ Open Association of eating behaviours with diurnal preference and rotating shift work in Japanese female nurses: a cross-sectional study
}

\author{
Takahiro Yoshizaki, ${ }^{1}$ Yukari Kawano, ${ }^{2}$ Osamu Noguchi, ${ }^{3}$ Junko Onishi, ${ }^{4}$ \\ Reiko Teramoto, ${ }^{5}$ Ayaka Sunami, ${ }^{6}$ Yuri Yokoyama, ${ }^{6}$ Yuki Tada, ${ }^{2}$ Azumi Hida, ${ }^{2}$ \\ Fumiharu Togo ${ }^{7}$
}

To cite: Yoshizaki T, Kawano Y, Noguchi 0, et al. Association of eating behaviours with diurnal preference and rotating shift work in Japanese female nurses: a cross-sectional study. BMJ Open 2016;6: e011987. doi:10.1136/ bmjopen-2016-011987

- Prepublication history for this paper is available online. To view these files please visit the journal online (http://dx.doi.org/10.1136/ bmjopen-2016-011987).

Received 21 March 2016 Revised 12 July 2016 Accepted 12 September 2016

CrossMark

For numbered affiliations see end of article.

Correspondence to Dr Takahiro Yoshizaki; yoshizaki@toyo.jp

\section{ABSTRACT}

Objectives: Our study examines differences in eating behaviour between day workers and rotating shift workers, and considers whether diurnal preference could explain the differences.

Methods: Japanese female nurses were studied (39 day workers and 123 rotating shift workers, aged 21-63 years) using self-administered questionnaires. The questionnaires assessed eating behaviours, diurnal preference and demographic characteristics. The questionnaire in the Guidelines for the management of obesity disease issued by the Japan Society for the Study of Obesity was used to obtain scores for the levels of obesity-related eating behaviours, including cognition of constitution, motivation for eating, eating as a diversion, feeling of satiety, eating style, meal contents and temporal eating patterns. The Japanese version of the Morningness-Eveningness (ME) questionnaire was used to measure self-rated preference for the degree to which people prefer to be active in the morning or the evening (ME).

Results: The scores for meal contents and temporal eating patterns in rotating shift workers were significantly higher than those in day workers. The ME score of rotating shift workers was significantly lower, indicating greater eveningness/less morningness among rotating shift workers. Multivariate linear regression revealed that the ME score was significantly negatively associated with temporal eating patterns and showed a negative association with the score for meal contents at a trend level, while current work shift was not significantly correlated with the scores.

Conclusions: These results suggest that eating behaviours for rotating shift workers are associated with a more unbalanced diet and abnormal temporal eating patterns and that the associations may be explained by diurnal preference rather than by rotating shift work.

\section{INTRODUCTION}

The growth in the proportion of the population aged 65 years and older leads to an

\section{Strengths and limitations of this study}

- There are few studies that have clarified whether the difference of diurnal preference explains changes in eating behaviours in rotating shift workers.

- The aim of the present study was to elucidate the differences in obesity-related eating behaviour between day workers and rotating shift workers, considering the diurnal preference, among Japanese female nurses.

- Eating behaviours for rotating shift workers were associated with more unbalanced diets and more abnormal temporal eating patterns, which may be explained by the diurnal preference rather than by rotating shift work.

- These findings have important implications for the development of novel strategies for preventing excessive weight gain in rotating shift workers.

- Variables, such as eating behaviours and diurnal preference, were self-reported. Continuous monitoring of dietary intake and the sleep-wake cycle may be needed in future research.

increase in the social demand for nurses in medical facilities. Among them, health problems can be caused by severe working conditions such as shifting of work schedules between the day and night (ie, rotating shift work). Previous studies have suggested that rotating shift work is related to higher risks of health problems, including obesity, increase in body mass index (BMI) and adiposity with abnormal metabolism, compared with fixed day work. ${ }^{1-3}$ One of the possible factors for increasing the risks of these health problems in rotating shift workers is their altered eating behaviour. ${ }^{4}{ }^{5}$ Our previous studies demonstrated that female workers who engaged in rotating shift work consumed more sugar-sweetened beverages 
and snacks than day workers, ${ }^{6}{ }^{7}$ and that the rate of persons who reported skipping breakfast almost every day $(80-100 \%)$ on days on the day shift was significantly higher in rotating shift workers compared with day workers. ${ }^{8}$ Recent studies by other groups have also showed that rotating shift workers had irregular meal times (eg, skipping meals or midnight snacks), ${ }^{9}$ and unbalanced dietary intake (eg, greater intake of fats and oils and lower intake of vegetables) when compared with day workers. ${ }^{10}$ However, it is unclear which aspects of obesity-related eating behaviour change in rotating shift workers and which factors contribute to the altered eating behaviours in rotating shift workers.

One plausible mechanism contributing to the altered eating behaviours in rotating shift workers is a disturbed circadian rhythm. Our previous study revealed that rotating shift workers had a significant phase delay in the 24 hours rhythm of cardiac autonomic nervous system activity compared with fixed day workers, ${ }^{11}$ suggesting a phase delay of the circadian rhythm among rotating shift workers. The endogenous circadian clocks, controlled by the master circadian clock in the suprachiasmatic nuclei of the hypothalamus, play a significant role in regulating a number of circadian and daily physiological rhythms, including feeding behaviour. ${ }^{12}$ For example, a human laboratory study showed that the circadian clock regulated hunger and appetite independently of the fasting-feeding rhythm and the sleep-wake cycle,${ }^{13}$ indicating that the phase delay of the circadian clock might modify the timing of eating. Moreover, a recent study revealed that a late midpoint of nocturnal sleep was associated with increases in energy intake from undesirable dietary contents such as alcoholic beverages, confectioneries, fats and oils and meats in individuals who did not engage in night shift work. ${ }^{14}$ Despite these available data, which suggest a possibility of a close association between eating behaviour and the circadian clock, there are few studies that have clarified whether the association explains changes in eating behaviours in rotating shift workers.

To investigate epidemiologically the phase of the circadian clock during daily life, individual preference in the sleep-wake cycle phase (ie, diurnal preference, morningness-eveningness (ME) or chronotype), which may be different from the actual sleep-wake cycle during daily life, was assessed using the Japanese version of the Morningness-Eveningness questionnaire by Torsvall and Akerstedt. ${ }^{15-18}$ Diurnal preference (eg, evening type or morning type) are attributed to differences in the phase of the circadian clock. ${ }^{19}$ Therefore, the aim of the present study was to elucidate the association between rotating shift work and obesity-related eating behaviours, considering the diurnal preference, among Japanese female nurses. Eating behaviours were investigated using the questionnaire in the Guidelines for the management of obesity disease issued by the Japan Society for the Study of Obesity. ${ }^{20}{ }^{21}$ Characteristics of eating behaviour which were different between overweight and normal weight individuals were extracted from a survey and compiled to produce the questionnaire. ${ }^{22}$ Our hypothesis was that rotating shift workers would have obesity-related eating behaviours associated with meal contents (eg, greater intake of specific nutrients) and temporal eating patterns (eg, skipping breakfast and/or late dinner), and that diurnal preference would partially explain the differences in obesity-related eating behaviours between day workers and rotating shift workers.

\section{METHODS}

\section{Participants}

The study population consisted of nurses working at a general hospital in the centre of Ome city. Ome city is located in the western side of Tokyo metropolitan area and is the fifth largest city in the metropolis. Urbanisation and industrialisation is present in the plains, while the districts in the hilly area in the western region of the city have rural populations. A total of 506 nurses were given the questionnaires by the chief nursing officer of each ward. The purpose of this study and data handling procedures were described in a covering letter with the questionnaire. Agreement to participate in this study was assumed on the basis of receipt of an anonymous questionnaire. A total of 218 nurses (43.1\%; age 19-63 years) responded. Among them, 56 were excluded from the analysis because of missing data (age $(n=2)$, current work schedules $(n=6)$, residential status $(n=1)$, marital status $(n=2)$, years of experience as a rotating shift worker $(n=23)$, smoking status $(n=2)$, alcohol status $(n=4)$, number of night shifts during the previous month $(\mathrm{n}=6)$ and the questionnaire about diurnal preference $(n=13))$. Since the scoring method for the questionnaire about obesity-related eating behaviour was different for men and women, ${ }^{23}{ }^{24}$ we decided to exclude the small data from male nurses $(n=20)$. As a result, 162 female nurses (39-day workers and 123 shift workers) were analysed (figure 1). Their mean total duration of experience in their current job was $12.2 \pm 10.3$ (SD) years. In this study, individuals who worked fixed day shifts only (ie, 08:30-17:15 hours) were defined as 'day workers', while those who worked in either a twoshift system (days and nights, at 08:30-17:15 and 16:3009:15 hours) or a forward-rotating three-shift system (days, evenings and nights, at 08:30-17:15, 16:30-01:00 and $00: 45-09: 15$, respectively) were classified as 'rotating shift workers'. The mean number of night shifts was 7.6 \pm 3.1 during the previous month.

\section{Assessments}

A cross-sectional study using self-administered questionnaires on demographic characteristics, diurnal preference and eating behaviour was conducted in the general hospital at the beginning of September 2012. Completed questionnaires were returned within 2 weeks. Demographic characteristics of the participants included in the questionnaire were the following: age, height, 


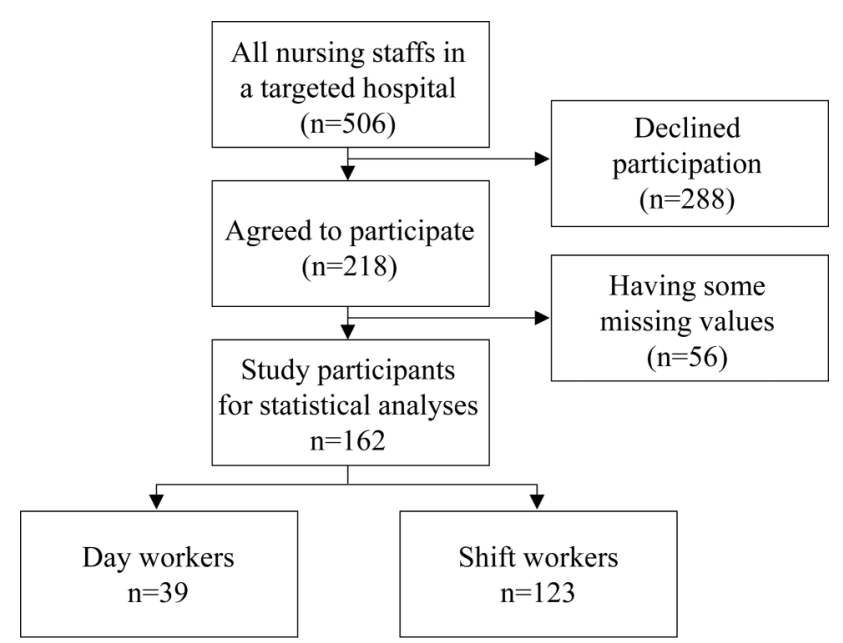

Figure 1 Flow chart of study participants.

weight, current work schedule, years of experience in the current job and as a rotating shift worker, marital status, residential status, smoking status, alcohol status and the number of night shifts during the previous month. Body mass index (BMI) was calculated on the basis of self-reported height and weight (weight/height ${ }^{2}$ $\left.\left(\mathrm{kg} / \mathrm{m}^{2}\right)\right)$. The Japanese version of the ME questionnaire by Torsvall and Akerstedt was used to measure selfrated preference for activity in the morning or the evening (ME). ${ }^{15} 1718$ Based on seven items about daily sleep habits or preference consisting of 0-3 Likert scales, the ME score was calculated (range: 7-28 points). A lower ME score indicates a tendency for a greater preference for activity in the evening (evening type), while a higher ME score indicates a greater preference for activity in the morning (morning type). We calculated the internal consistency for the ME questionnaire using the present data, which revealed a Cronbach's $\alpha$ of 0.73 . Data about habitual eating behaviours during the previous month were obtained from the response to the eating behaviour questionnaire issued by the Japan Society for the Study of Obesity, ${ }^{20}{ }^{21}$ which was developed to detect obesity-related eating behaviour. The details of the contents of the questionnaire have been shown in previous studies. ${ }^{22} 232526$ In brief, each of the 55 items on eating habits is rated on a four-point scale ranging from 'strongly disagree' to 'strongly agree'. These items form seven separate scales: cognition of constitution (range: 6-24), motivation for eating (range: 9-36), eating as a diversion (range: 4-16), feeling of satiety (range: 6-24), eating style (range: 5-20), meal contents (range: 7-28) and temporal eating patterns (range: 8-32). Higher scores indicate more improper eating behaviour in terms of a higher probability of obesity. ${ }^{22}{ }^{23}$ We also calculated the internal consistency using the data in this study, with Cronbach's $\alpha$ found to be 0.62 for cognition of constitution, 0.82 for motivation for eating, 0.71 for eating as diversion, 0.63 for feeling of satiety, 0.82 for eating style, 0.77 for meal contents and 0.71 for temporal eating patterns.

\section{Statistical analysis}

After the normal distribution of variables had been tested by Kolmogorov-Smirnov test, the t-test or Mann-Whitney U test and the $\chi^{2}$ test or Fisher's exact test were used for continuous and categorical variables, respectively, to compare the difference in demographic characteristics, the ME score and the scores for eating behaviour between day workers and rotating shift workers. For categorical variables, residuals between the observed and expected frequencies were standardised to determine cells which were statistically different from expected values. Effect sizes for the difference in the scores of eating behaviour between the groups were assessed using Cohen's d. Simple and multivariate linear regressions (model 1) were performed with each score for eating behaviour (meal contents or temporal eating patterns) as dependent variables, and current work schedule $(0=$ day work, $1=$ rotating shift work $)$ and the ME score (continuous, in points) as independent variables. The model was extended (model 2) using an interaction term (shift work $\times$ ME score) with the following demographic characteristics for covariate adjustment: age (continuous, in years), years of experience as a rotating shift worker (continuous, in years), marital status $(0=$ married, $1=$ unmarried or divorced $)$, residential status ( $0=$ living alone, $1=$ not living alone), smoking status ('Do you smoke?'; $0=$ no, $1=$ yes), alcohol status ('Do you drink alcohol?'; $0=$ no, 1=yes) and the number of night shifts during the previous month (continuous, in days). All statistical analyses were performed with an SPSS statistical software package (IBM SPSS V.22.0 for Windows, SPSS Japan). p Values $<0.05$ were considered statistically significant using two-tailed tests.

\section{RESULTS}

The demographic characteristics of day workers and rotating shift workers are shown in table 1 . Age was significantly higher in day workers compared with rotating shift workers $(p<0.05)$. The years of experience in the current work schedule were significantly more in day workers compared with rotating shift workers $(p<0.05)$. Marital status and residential status were significantly associated with the current work schedule $(p<0.05)$. The ME score for rotating shift workers was significantly lower compared with day workers $(p<0.05)$, indicating greater eveningness/less morningness among rotating shift workers compared with day workers. This significant difference was not attenuated after controlling for age as a confounding variable (data not shown).

Scores for the obesity-related eating behaviours of day workers and rotating shift workers are shown in table 2 . The scores for meal contents and temporal eating patterns significantly differed between the groups $(p<0.05)$, indicating an unbalanced diet and more irregular timing of meals among rotating shift workers compared with day workers. Scores for other eating behaviours did not differ between the groups $(p>0.05)$. 
Table 1 Demographic characteristics of day workers and rotating shift workers

\begin{tabular}{|c|c|c|c|}
\hline & $\begin{array}{l}\text { Day workers } \\
\mathrm{n}=39\end{array}$ & $\begin{array}{l}\text { Shift workers } \\
\mathrm{n}=123\end{array}$ & p Values \\
\hline Age† (years) & $44.2 \pm 10.9$ & $34.7 \pm 8.7$ & $<0.001$ \\
\hline Height†‡ (cm) & $156.7 \pm 5.6$ & $157.5 \pm 5.5$ & 0.175 \\
\hline Weight†§ (kg) & $53.4 \pm 8.3$ & $53.8 \pm 8.9$ & 0.784 \\
\hline BMI†ף $\left(\mathrm{kg} / \mathrm{m}^{2}\right)$ & $21.7 \pm 2.7$ & $21.7 \pm 3.5$ & 0.676 \\
\hline ME score $\dagger^{\star *}$ (points) & $20.8 \pm 3.3$ & $17.1 \pm 4.0$ & $<0.001$ \\
\hline \multicolumn{4}{|l|}{ Years of experience } \\
\hline Current work† (years) & $17.4 \pm 12.0$ & $10.6 \pm 9.2$ & 0.002 \\
\hline Rotating shift work† (years) & $11.8 \pm 10.7$ & $9.7 \pm 8.7$ & 0.652 \\
\hline Number of night shifts (day/month) & $0.0 \pm 0.0$ & $7.6 \pm 3.1$ & - \\
\hline \multicolumn{4}{|l|}{ Marital status $\dagger$} \\
\hline Married & $32(82)^{*}$ & $50(41)^{*}$ & \multirow[t]{2}{*}{0.001} \\
\hline Unmarried or divorced & $7(18)$ & $73(59)$ & \\
\hline \multicolumn{4}{|l|}{ Residential status †† } \\
\hline Living alone & $3(8)$ & $33(27)^{*}$ & \multirow[t]{2}{*}{0.014} \\
\hline Not living alone & $36(92)^{*}$ & $90(73)$ & \\
\hline \multicolumn{4}{|l|}{ Smoking status } \\
\hline Yes & $4(10)$ & $17(14)$ & \multirow[t]{2}{*}{0.785} \\
\hline No & $35(90)$ & $106(86)$ & \\
\hline \multicolumn{4}{|l|}{ Alcohol status†† } \\
\hline Yes & $21(54)$ & $51(41)$ & \multirow[t]{2}{*}{0.198} \\
\hline No & $18(46)$ & $72(59)$ & \\
\hline 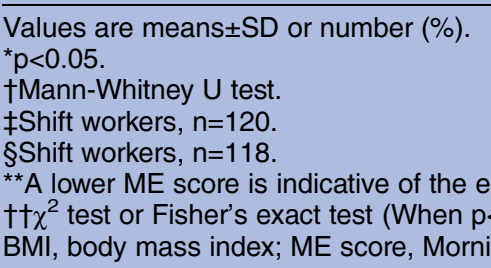 & residuals were & cell.). & \\
\hline
\end{tabular}

Table 2 Scores for habitual eating behaviour in day workers and rotating shift workers

\begin{tabular}{|c|c|c|c|c|c|}
\hline & $\begin{array}{l}\text { Normal } \\
\text { (Ref. 23) }\end{array}$ & $\begin{array}{l}\text { Day workers } \\
\mathrm{n}=39\end{array}$ & $\begin{array}{l}\text { Shift workers } \\
n=123\end{array}$ & Cohen's d & p Values \\
\hline Cognition of constitution* $\dagger$ (points) & 14 & $14.3 \pm 3.4$ & $13.6 \pm 3.7$ & -0.19 & 0.328 \\
\hline Motivation for eating $\ddagger \S$ (points) & 18 & $19.5 \pm 4.9$ & $18.8 \pm 5.6$ & -0.13 & 0.384 \\
\hline Eating as a diversion $\ddagger \rrbracket$ (points) & 7 & $7.4 \pm 2.4$ & $7.1 \pm 2.9$ & -0.11 & 0.310 \\
\hline Feeling of satiety $\ddagger$ (points) & 10 & $10.9 \pm 3.1$ & $11.3 \pm 3.2$ & 0.13 & 0.427 \\
\hline Eating style & 9 & $9.8 \pm 3.5$ & $9.7 \pm 3.6$ & -0.03 & 0.629 \\
\hline Meal contents $\ddagger$ (points) & 12 & $13.9 \pm 3.9$ & $15.6 \pm 4.5$ & 0.39 & 0.045 \\
\hline Temporal eating patterns $\ddagger^{\star *}$ (points) & 16 & $16.5 \pm 4.5$ & $19.5 \pm 4.8$ & 0.63 & 0.001 \\
\hline
\end{tabular}

Values are means \pm SD.

Higher scores indicate more improper eating behaviour in terms of a higher probability of obesity: Cognition of weight and constitution, having false recognition of and assumptions about reasons for weight gain; Motivation for eating, having behavioural factors which can induce over-eating; Eating as a diversion, being subject to psychological factors which increase appetite (ie, perceived mental stress); Feeling of satiety, being prone to have an appetite and to eat as much as possible; Eating style, being prone to eat fast; Meal contents, having a preference for a high fat diet and sweets (eg, confectioneries and sweet buns); Temporal eating patterns, irregularity of timing and number of meals taken during the day and delay in timing of meals.

*t-test.

‡Mann-Whitney $\mathrm{U}$ test.

$\S$ Shift workers, $n=122$.

IDay workers, $n=38$.

**Shift workers, $n=119$.

We examined the relationship between rotating shift work, the ME score and scores for meal contents and temporal eating patterns using simple and multivariate linear regression. Simple linear regression (table 3 , figure 2) showed that rotating shift work and a lower ME score were significantly $(\mathrm{p}<0.05)$ associated with higher 
Table 3 Association of current shift schedule (rotating shift work) and diurnal preference with scores for meal contents and temporal eating patterns in multivariate linear regression models

\begin{tabular}{|c|c|c|c|c|}
\hline \multirow[b]{2}{*}{ Independent variables } & \multicolumn{2}{|c|}{$\begin{array}{l}\text { Unstandardised } \\
\text { coefficients }\end{array}$} & \multirow{2}{*}{$\begin{array}{l}\text { Standardised coefficients } \\
\boldsymbol{\beta}\end{array}$} & \multirow[b]{2}{*}{ p Values } \\
\hline & B & SE & & \\
\hline \multicolumn{5}{|l|}{ Meal contents } \\
\hline \multicolumn{5}{|l|}{ Crude } \\
\hline Rotating shift work & 1.689 & 0.804 & 0.164 & 0.037 \\
\hline ME score & -0.223 & 0.082 & -0.210 & 0.007 \\
\hline \multicolumn{5}{|l|}{ Model 1} \\
\hline Rotating shift work & 1.007 & 0.862 & 0.098 & 0.245 \\
\hline ME score & -0.183 & 0.089 & -0.172 & 0.041 \\
\hline \multicolumn{5}{|l|}{ Model $2^{*}$} \\
\hline Rotating shift work & 1.486 & 1.441 & 0.144 & 0.304 \\
\hline ME score & -0.208 & 0.106 & -0.196 & 0.051 \\
\hline Shift work×ME score & 0.222 & 0.247 & 0.100 & 0.371 \\
\hline \multicolumn{5}{|l|}{ Temporal eating patterns } \\
\hline \multicolumn{5}{|l|}{ Crude } \\
\hline Rotating shift work & 3.211 & 0.867 & 0.284 & $<0.001$ \\
\hline ME score & -0.465 & 0.086 & -0.397 & $<0.001$ \\
\hline \multicolumn{5}{|l|}{ Model 1} \\
\hline Rotating shift work & 1.698 & 0.897 & 0.150 & 0.060 \\
\hline ME score & -0.395 & 0.093 & -0.338 & $<0.001$ \\
\hline \multicolumn{5}{|l|}{ Model $2^{*}$} \\
\hline Rotating shift work & 1.426 & 1.500 & 0.126 & 0.342 \\
\hline ME score & -0.395 & 0.110 & -0.338 & $<0.001$ \\
\hline Shift work $\times$ ME score & -0.061 & 0.255 & -0.025 & 0.811 \\
\hline
\end{tabular}
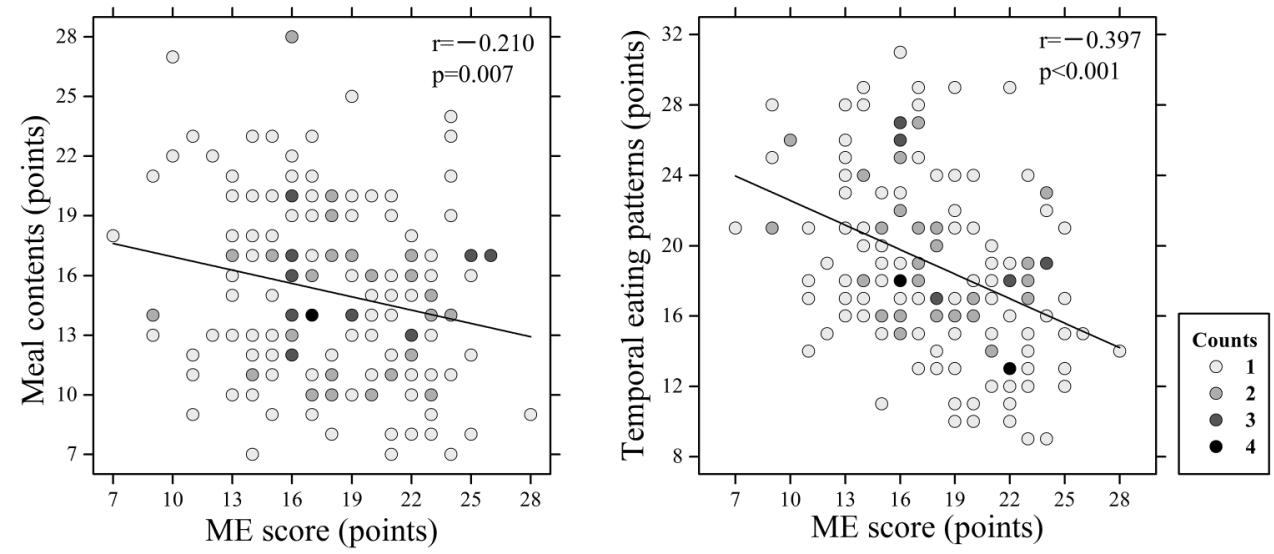

Figure 2 The relationship between the Morningness-Eveningness (ME) score and the meal contents and temporal eating patterns scores.

scores for meal contents and temporal eating patterns. Multivariate linear regression (model 1) showed that the ME score was significantly $(p<0.05)$ associated with the score for meal contents, while the effect of rotating shift work was not $(p=0.245)$. Regarding temporal eating patterns, the ME score was significantly associated with the score $(p<0.05)$, while rotating shift work was attenuated to a trend level only $(\mathrm{p}=0.060)$. In model 2 , in which the variables of demographic characteristics $(p<0.05)$ differed significantly between the groups (ie, age, years of experience as a rotating shift worker, marital status, residential status, and number of night shifts during the previous month) and smoking and alcohol status were controlled, the correlations with the ME score decreased slightly but remained significantly negative $(\beta=-0.338$, $\mathrm{p}<0.05$ ) for temporal eating patterns or at a trend level $(\beta=-0.196, p=0.051)$ for meal contents, while there were no significant interactions between shift work and the ME score with the scores for meal contents and temporal eating patterns. 


\section{DISCUSSION}

Our cross-sectional study explored the differences in obesity-related eating behaviour between day workers and rotating shift workers, considering diurnal preference, among Japanese female nurses. Scores for meal contents and temporal eating patterns were significantly higher in rotating shift workers than in day workers $(p<0.05)$. The ME score of rotating shift workers was significantly $(p<0.05)$ lower compared with day workers, indicating greater eveningness/less morningness among rotating shift workers. Multivariate linear regression revealed that the correlation with the ME score was significantly negative $(\beta=-0.338, p<0.05)$ for the score for temporal eating patterns and showed a negative association with the score for meal contents at a trend level $(\beta=-0.196, p=0.051)$, while current work shift (ie, rotating shift work) was not significantly correlated with the scores. These results suggest that eating behaviours for rotating shift workers are associated with a more unbalanced diet and abnormal temporal eating patterns and that the associations could be explained by diurnal preference (eg, greater eveningness/less morningness) rather than by rotating shift work. To the best of our knowledge, this is the first study to show the associations between rotating shift work, diurnal preference and eating behaviour.

Given the fact that the evening type closely correlates with delays in the phase angle of the circadian rhythm ${ }^{19}$ and that the phase delay can be caused by light exposure and sleep/dark schedules during nights on the days of the night shift, ${ }^{27}$ our study indicates that being of greater eveningness/less morningness, or the phase delay of the circadian rhythm, may correlate with altered eating behaviour in rotating shift workers. This indication is supported by previous studies. ${ }^{11}{ }^{28}$ For example, one previous study revealed that rotating shift workers showed a phase delay in the circadian rhythm compared with day workers. ${ }^{11}$ In addition, rotating shift workers have a tendency for more evening types compared with day workers, ${ }^{8}{ }^{29}$ which is consistent with our results. We also demonstrated that a greater phase delay of the circadian rhythm was associated with a later timing of breakfast among rotating shift workers. ${ }^{28}$ However, causality between diurnal preference or phase angle of the circadian rhythm and altered eating behaviour could not be examined, although these may have interactive effects. It should be explored in future studies whether changes from the evening type to the morning type in diurnal preference or the phase advance of the circadian rhythm would improve eating behaviour in rotating shift workers.

Our results show that rotating shift work is associated with higher scores for meal contents and temporal eating patterns. A higher score for meal contents represents a greater preference for a high-fat diet and sweets (eg, confectioneries and sweet buns). ${ }^{21} 2325$ A higher score for temporal eating patterns represents a greater irregularity in the timing and number of meals consumed and a later timing of meals. ${ }^{21} 23$ Consistent with these changes in obesity-related eating behaviour in rotating shift workers, our previous studies have shown that rotating shift workers consumed more confectioneries and sugar-sweetened beverages compared with day workers, ${ }^{7}$ and that the rate of skipping breakfast on days on the day shift in rotating shift workers was significantly higher compared with day workers among female nurses $^{8}$ in large population studies. Furthermore, the preference for a high-fat diet was confirmed following a simulated night shift. ${ }^{30}$

Chronic positive energy balance is one of the wellknown causes of lifestyle-related diseases which are mediated by obesity. The positive energy balance is caused by the excess dietary intake relative to energy expenditure, and can be relatively easily induced by consuming large portions of food ${ }^{31}$ and/or high energydense food such as snacks and confectioneries. ${ }^{32}$ In our samples, the score for meal contents was significantly and positively associated with BMI (Pearson's correlation $=0.186, p=0.031$ ). Recently, studies have shown that the timing of meal intake (ie, skipping breakfast, greater caloric intake at dinner or later timing of dinner) also contributed to increases in BMI and the higher risk of obesity, ${ }^{5} 33$ after statistically controlling for total energy intake, in individuals who do not engage in night shift work. In our samples, the score for temporal dietary patterns was significantly and positively associated with BMI (Pearson's correlation $=0.281, \mathrm{p}=0.005$ ). Regarding rotating shift workers, it has been found that nocturnal energy intake (00:00-04:00) on days on the night shift was associated with increases in body weight. ${ }^{34}$ Another recent study found that the significant effects of rotating shift work on BMI remained after controlling for daily total energy intake and daily physical activity. ${ }^{7}$ With regard to the physiological background of these relations, the timing of meals might change the lipid metabolism. ${ }^{45}{ }^{36}$ Considered together with higher scores for meal contents and temporal eating patterns in rotating shift workers (table 2) compared with those scores of day workers and normal-weight women ${ }^{23}$ the timing of meal intake, as well as meal contents, may be an important factor in prevention and improvement of obesity and lifestyle-related diseases in rotating shift workers and this should be examined in the future. In particular, studies on the effects of the timing of meal intake on days on the night shift on BMI may be needed.

The means of BMI for day workers and rotating shift workers in our samples were not significantly different and fell in the normal range of BMI. However, it should be noted that age was significantly higher in day workers, and that years of experience of rotating shift work were significantly longer in day workers compared with rotating shift workers (table 1). Previous studies have indicated that the duration of rotating shift work may have a positive relationship with overweight/ obesity $^{37}$ and increasing BMI, ${ }^{7}$ indicating that there may be cumulative effects of rotating shift work on BMI in 
day workers (table.1). In addition, in Japan, more than $20 \%$ of women in their 20s are underweight $\left(\mathrm{BMI}<18.5 \mathrm{~kg} / \mathrm{m}^{2}\right) .^{38}$ This percentage is much higher than in most developed countries. ${ }^{39}$ Also, in epidemiological studies using a larger sample size, mean BMI scores for rotating shift workers in Japanese female nurses (eg, Tada et al; $21.6 \pm 3.2 \mathrm{~kg} / \mathrm{m}^{2}, \mathrm{n}=1579 ;^{7}$ Lee et $\left.a t^{40} ; 22.3 \pm 3.0 \mathrm{~kg} / \mathrm{m}^{2}, \mathrm{n}=18108\right)$ were in the normal range, while this value in other countries was higher than the normal range (eg, Australian and New Zealand nurses; $26.4 \pm 5.3 \mathrm{~kg} / \mathrm{m}^{2}, \mathrm{n}=320{ }^{41}$ Canadian nurses; 25.7 $\left.\pm 5.1 \mathrm{~kg} / \mathrm{m}^{2}, \mathrm{n}=4111^{42}\right)$. Considered together with the higher percentage of body fat levels, especially at lower BMI, in Japanese compared with Caucasians and African-Americans, ${ }^{43}$ Japanese female nurses engaging in rotating shift work should be careful of gains in BMI and/or the percentage of body fat as well as BMI.

There were several limitations to this study. First, variables, such as eating behaviours and diurnal preference, were self-reported. Continuous monitoring of dietary intake and the sleep-wake cycle may be needed in future research. Second, the effect of other rotating shift systems on eating behaviours remains unclear. Morikawa et $a l^{44}$ reported that people working on a rotating two-shift system had a higher risk of increased BMI compared with people working on a rotating three-shift system, indicating that the type of rotating shift system might affect eating behaviour. Third, the current participants were all Japanese female nurses at a particular city hospital. Studies in other populations may be required to clarify to what extent the present results can be generalised. Fourth, the unbalanced sample size between day and shift workers may have contributed to a decrease in the statistical power to detect significant differences in dietary behaviours between the groups, even though we could not detect differences of a negligible effect size (absolute Cohen's $\mathrm{d}<0.15$ ) or a lower range of a small effect size $(0.15 \leq$ absolute Cohen's $\mathrm{d}<0.02)$ using statistical tests. Finally, potential confounding variables, such as habitual sleep duration, daily variation in sleep timing, psychological stress and sensations of fatigue, may not have been fully considered.

\section{Conclusions}

In conclusion, eating behaviours for rotating shift workers were associated with more unbalanced diets and more abnormal temporal eating patterns, which may be explained by the diurnal preference rather than by rotating shift work. These findings have important implications for the development of novel strategies for preventing excessive weight gain in rotating shift workers.

\footnotetext{
Author affiliations

${ }^{1}$ Faculty of Food and Nutritional Sciences, Toyo University, Gunma, Japan ${ }^{2}$ Faculty of Applied Bio-Science, Department of Nutritional Science, Tokyo University of Agriculture, Tokyo, Japan

${ }^{3}$ Department of Gastroenterology, Ome City General Hospital, Tokyo, Japan

${ }^{4}$ Department of Nursing, Ome City General Hospital, Tokyo, Japan

${ }^{5}$ Department of Clinical Nutrition, Ome City General Hospital, Tokyo, Japan
}

${ }^{6}$ Graduate School of Agriculture, Tokyo University of Agriculture, Tokyo, Japan ${ }^{7}$ Educational Physiology Laboratory, Graduate School of Education, The University of Tokyo, Tokyo, Japan

Acknowledgements The authors thank the chief nurses and staff of each medical ward in Ome City General Hospital, and all persons who cooperated in conducting this study.

Contributors TY, YK, ON, JO, RT and FT designed the research. TY, AS, YY, $\mathrm{AH}$ and $\mathrm{YT}$ conducted the research. TY, YT and FT analysed the data. TY, YK and FT wrote the manuscript. TY had primary responsibility for the final content. All the authors read and approved the final manuscript.

Funding This study was supported by a grant from the Japan Society for the Promotion of Science (Grant-in-Aid for start-up 26882040).

\section{Competing interests None declared.}

Patient consent Obtained.

Ethics approval All the study procedures were reviewed and approved by the Ethics Committee at the Tokyo University of Agriculture (number 1111).

Provenance and peer review Not commissioned; externally peer reviewed.

Data sharing statement No additional data are available.

Open Access This is an Open Access article distributed in accordance with the Creative Commons Attribution Non Commercial (CC BY-NC 4.0) license, which permits others to distribute, remix, adapt, build upon this work noncommercially, and license their derivative works on different terms, provided the original work is properly cited and the use is non-commercial. See: http:// creativecommons.org/licenses/by-nc/4.0/

\section{REFERENCES}

1. De Bacquer D, Van Risseghem M, Clays E, et al. Rotating shift work and the metabolic syndrome: a prospective study. Int J Epidemiol 2009;38:848-54.

2. Knutsson A. Health disorders of shift workers. Occup Med (Lond) 2003;53:103-8.

3. Suwazono $\mathrm{Y}$, Dochi $\mathrm{M}$, Sakata $\mathrm{K}$, et al. A longitudinal study on the effect of shift work on weight gain in male Japanese workers. Obesity (Silver Spring) 2008;16:1887-93.

4. Smith KJ, Gall SL, McNaughton SA, et al. Skipping breakfast: longitudinal associations with cardiometabolic risk factors in the Childhood Determinants of Adult Health Study. Am J Clin Nutr 2010;92:1316-25.

5. Bo S, Musso G, Beccuti G, et al. Consuming more of daily caloric intake at dinner predisposes to obesity. A 6-year population-based prospective cohort study. PLOS ONE 2014;9:e108467.

6. Yoshizaki T, Tada Y, Kodama T, et al. Influence of shiftwork on association between body mass index and lifestyle or dietary habits in female nurses and caregivers. J Jpn Soc Nutr Food Sci 2010;63:161-7.

7. Tada Y, Kawano Y, Maeda I, et al. Association of body mass index with lifestyle and rotating shift work in Japanese female nurses. Obesity (Silver Spring) 2014;22:2489-93.

8. Togo F, Yoshizaki T, Komatsu T. Associations of depressive symptoms with sleep duration, chronotype, and skipping breakfast in rotating shift workers. SLEEP (Abstract Supplement) 2015: A324-325.

9. Fukumura T, Yoshita K, Tabata M. Associations among physical condition, life hour, and dietary intake Male Japanese shift workers: physical condition and lifestyle survey of male Japanese shift workers. Sangyo Eiseigaku Zasshi 2015;57:286-96.

10. Hemiö K, Puttonen S, Viitasalo K, et al. Food and nutrient intake among workers with different shift systems. Occup Environ Med 2015;72:513-20.

11. Yoshizaki T, Kawano Y, Tada Y, et al. Diurnal 24-hour rhythm in ambulatory heart rate variability during the day shift in rotating shift workers. J Biol Rhythms 2013;28:227-36.

12. Hastings $\mathrm{MH}$, Reddy $\mathrm{AB}$, Maywood ES. A clockwork web: circadian timing in brain and periphery, in health and disease. Nat Rev Neurosci 2003;4:649-61.

13. Scheer FAJL, Morris CJ, Shea SA. The internal circadian clock increases hunger and appetite in the evening independent of food intake and other behaviors. Obesity (Silver Spring) 2013;21:421-3. 
14. Sato-Mito N, Sasaki S, Murakami K, et al. The midpoint of sleep is associated with dietary intake and dietary behavior among young Japanese women. Sleep Med 2011;12:289-94.

15. Torsvall L, Akerstedt T. A diurnal type scale. Construction, consistency and validation in shift work. Scand J Work Environ Health 1980;6:283-90

16. Yamaguchi $M$, Watanabe $T$, Takagi $A$, et al. Morningness-eveningness preference and the autonomic nervous system activity in the morning among female university students. $J$ Jp Soc Psychosom Obstet Gynecol 2011;16:160-8.

17. Nakade $M$, Takeuchi $\mathrm{H}$, Kurotani $M$, et al. Effects of meal habits and alcohol/cigarette consumption on morningness-eveningness preference and sleep habits by Japanese female students aged 18-29. J Physiol Anthropol 2009;28:83-90.

18. Chiba Y, Takahashi K. Chronobiology handbook. Tokyo: Asakura-shoten (in Japanese), 1991.

19. Baehr EK, Revelle W, Eastman Cl. Individual differences in the phase and amplitude of the human circadian temperature rhythm: with an emphasis on morningness-eveningness. J Sleep Res 2000;9:117-27.

20. Japan Society for the Study of Obesity. Guideline for the management of obesity dissease. 2006

21. Japan Society for the Study of Obesity. Guideline for the management of obesity disease. 2016.

22. Okuma K, Sakata T. Treatment of obesity with diabetes melitus. Jpn J Clin Exp Med 2002;79:89-93.

23. Okuma K, Okuma M. Behavioral modification therapy. Nippon Rinsho 2003;61:631-9.

24. Ohmori Y, Suzuki N, Morita A, et al. Association of Personality (NEO-Five Factor Inventory) with Eating Behaviors and Physical Activity Levels in Obese Subjects in the Saku Control Obesity Program (SCOP). Anti-Ageing Med 2007;4:43-50.

25. Kawabata N, Matsushima M, Yuasa A, et al. Relationship between feeding deflection and food intake in Japanese subjects with type 2 diabetes. J Japan Diab Soc (in Japanese) 2009;52:757-65.

26. Fujishima $\mathrm{Y}$, Maeda N, Inoue $\mathrm{K}$, et al. Efficacy of liraglutide, a glucagon-like peptide-1 (GLP-1) analogue, on body weight, eating behavior, and glycemic control, in Japanese obese type 2 diabetes. Cardiovasc Diabetol 2012;11:107.

27. Santhi N, Duffy JF, Horowitz TS, et al. Scheduling of sleep/darkness affects the circadian phase of night shift workers. Neurosci Lett 2005;384:316-20.

28. Yoshizaki T, Midorikawa T, Hasegawa K, et al. Associations between diurnal 24-hour rhythm in ambulatory heart rate variability and the timing and amount of meals during the day shift in rotating shift workers. PLOS ONE 2014;9:e106643.

29. Bhatti $P$, Mirick DK, Davis S. The impact of chronotype on melatonin levels among shift workers. Occup Environ Med 2014;71:195-200.
30. Cain SW, Filtness AJ, Phillips CL, et al. Enhanced preference for high-fat foods following a simulated night shift. Scand $J$ Work Environ Health 2015;41:288-93.

31. English L, Lasschuijt M, Keller KL. Mechanisms of the portion size effect. What is known and where do we go from here? Appetite 2015;88:39-49.

32. McCrory MA, Fuss PJ, McCallum JE, et al. Dietary variety within food groups: association with energy intake and body fatness in men and women. Am J Clin Nutr 1999;69:440-7.

33. Ma Y, Bertone ER, Stanek EJ, III, et al. Association between eating patterns and obesity in a free-living US adult population. Am $J$ Epidemiol 2003;158:85-92.

34. Tada $\mathrm{Y}$, Matsumoto $\mathrm{H}$, Yoshizaki $\mathrm{T}$, et al. Correlation between dietary intake and weight gain among female rotating shift workers at long-term healthcare facilities. Jpn J Cardiovasc Dis Prev 2012;47:1-12.

35. Yoshizaki T, Tada Y, Hida A, et al. Effects of feeding schedule changes on the circadian phase of the cardiac autonomic nervous system and serum lipid levels. Eur J Appl Physiol 2013;113:2603-11.

36. Yoshida C, Shikata N, Seki S, et al. Early nocturnal meal skipping alters the peripheral clock and increases lipogenesis in mice. Nutr Metab 2012;9:78

37. Kim MJ, Son KH, Park HY, et al. Association between shift work and obesity among female nurses: Korean Nurses' Survey. BMC Public Health 2013;13:1204.

38. Ministry of Health, Labour and Welfare, National health and nutrition examination survey in 2013. http://www.mhlw.go.jp/bunya/kenkou/ eiyou/h25-houkoku.htm

39. Sugawara A, Saito K, Sato M, et al. Thinness in Japanese young women. Epidemiology 2009;20:464-5.

40. Lee JS, Hayashi K, Mishra G, et al. Independent association between age at natural menopause and hypercholesterolemia, hypertension, and diabetes mellitus: Japan nurses' health study. $J$ Atheroscler Thromb 2013;20:161-9.

41. Tuckett A, Henwood T, Oliffe JL, et al. A Comparative Study of Australian and New Zealand Male and Female Nurses' Health: a Sex Comparison and Gender Analysis. Am J Mens Health 2016;10:450-8.

42. Smith $\mathrm{P}$, Fritschi $\mathrm{L}$, Reid $\mathrm{A}$, et al. The relationship between shift work and body mass index among Canadian nurses. Appl Nurs Res 2013;26:24-31.

43. Deurenberg P, Deurenberg-Yap M, Guricci S. Asians are different from Caucasians and from each other in their body mass index/body fat per cent relationship. Obes Rev 2002;3:141-6.

44. Morikawa $\mathrm{Y}$, Nakagawa $\mathrm{H}$, Miura $\mathrm{K}$, et al. Shift work and the risk of diabetes mellitus among Japanese male factory workers. Scand $J$ Work Environ Health 2005;31:179-83. 